\title{
ANALISIS KENAIKAN MUKA AIR LAUT INDONESIA TAHUN 1993-2018 MENGGUNAKAN DATA ALTIMETRI
}

\author{
Eko Yuli Handoko ${ }^{1}$, Yuwono ${ }^{2}$, Reny Ariani $^{3}$ \\ 1,2,3 Departemen Teknik Geomatika, FTSLK-ITS, Kampus ITS Sukolilo, Surabaya, 60111, Indonesia \\ e-mail: ${ }^{1}$ ekoyh@geodesy.its.ac.id
}

\begin{abstract}
Abstrak
Kenaikan muka air laut (sea level rise) merupakan konsekuensi dari perubahan iklim yang memiliki dampak signifikan terhadap kehidupan sosial, ekonomi, dan infrastruktur, serta ancaman tenggelamnya kawasan pesisir Indonesia yang ditinggali oleh $60 \%$ penduduknya. Sejak akhir abad ke-19, perubahan kedudukan air laut diamati dari stasiun pasang surut di sepanjang garis pantai. Namun, pengamatan stasiun pasang surut memiliki keterbatasan dalam jumlah, distribusi, dan jangkauannya, serta adanya pengaruh land subsidence. Oleh karena itu, penelitian ini menganalisis tren kenaikan muka air laut Indonesia menggunakan data pengamatan misi referensi satelit altimetri, yaitu Topex/Poseidon, Jason 1, Jason 2, dan Jason 3. Setelah dilakukan least square intercalibrated dan a-seasonal-trend decomposition procedure based on loess diketahui bahwa laju sea level rise di Indonesia $+4,5 \mathrm{~mm} /$ tahun pada periode tahun 1993 2018. Tren linier bernilai positif ini menunjukkan bahwa ketinggian muka laut di Indonesia akan terus meningkat dengan persamaan $y=4,6 x-9133,5 \mathrm{~mm}$, dimana y adalah sea level anomaly dan $x$ adalah waktu. Sehingga berdasarkan hasil tersebut dapat dilakukan perencanaan pra-kejadian terhadap dampak dari sea level rise yang akan mendatang.
\end{abstract}

Kata kunci : Altimetri, Intercalibrated, Sea level, Loess

\begin{abstract}
Sea level rise is a consequence of climate change which has a significant impact on social life, economy, and infrastructure, as well as the threat of sinking of Indonesia's coastal areas inhabited by $60 \%$ of its population. Since the end of the 19th century, changes in sea level were observed from tidal stations along the coastline. However, tidal station observations have limitations in number, distribution, and range, as well as the influence of land subsidence. Therefore, this study analyzes the trend of rising sea levels in Indonesia using observational data altimetry satellite reference missions, namely Topex / Poseidon, Jason 1, Jason 2, and Jason 3. After least square intercalibrated and a-seasonal-trend decomposition procedure based on loess it is known that the rate of sea level rise in Indonesia is $+4.5 \mathrm{~mm} /$ year in the period 1993-2018. This positive linear trend shows that sea level in Indonesia will continue to increase with the equation $y=4.6 x-9133.5 \mathrm{~mm}$, where $y$ is the sea level anomaly and $x$ is time. Thus, based on these results a pre-event planning can be carried out on the impact of the upcoming sea level rise.
\end{abstract}

Keywords : Altimetry, Intercalibrated, Sea level, Loess 


\section{PENDAHULUAN}

Sea level rise atau kenaikan muka air laut sebagai konsekuensi dari perubahan iklim menjadi masalah serius bagi penduduk daerah pesisir. Kenaikan air laut dapat menyebabkan penggenangan daerah dataran rendah, banjir, dan intrusi air laut ke akuifer (Nicholls, 2010). Selain itu, kenaikan muka air laut memiliki dampak signifikan terhadap sosioekonomi nasional, infrastruktur dan lingkungan, serta ancaman tenggekamnya daataran di sekitar wilayah pesisir, yang telah menjadi tempat tinggal sekitar $75 \%$ penduduk di kawasan Asia Pasifik. Sedangkan, Asia Pasifik sendiri merupakan tempat tinggal oleh lebih dari separuh penduduk dunia (McGranahan, et.al., 2007).

Kawasan pesisir Indonesia sendiri ditinggali oleh $60 \%$ penduduknya. Aktivitas di wilayah pesisir juga berfungsi secara sosial dan ekonomi, yaitu karena sebagian wilayah pesisir merupakan kotakota besar. Sebagian lainnya, wilayah pesisir Indoensia digunakan sebagai pusat perdagangan nelayan dan juga pariwisata. Selain itu, wilayah pesisir biasa digunakan sebagai dermaga atau penghubung antar pulau, sehingga infrastruktur di wilayah pesisir bernilai ekonomi tinggi. Oleh karena itu, dampak yang signifikan dari adanya kenaikan muka air laut akan menjadi permasalahan jangka panjang bagi Indonesia. Terlepas dari wilayah pesisirnya, lokasi geografis Indonesia yang berada antara Samudera Hindia dan Samudera Pasifik, serta antara Benua Asia dan Benua Australia, membuat tingkat mobilisasi perdagangan menggunakan jalur laut di Indonesia sangat padat. Sehingga, fenomena yang terjadi di laut sangat penting untuk dipelajari (Dahuri, et.al., 2008).

Sejak akhir abad ke-19, perubahan kedudukan air laut diamati dari stasiun pasang surut di sepanjang garis pantai (Church and White, 2011). Namun, pengamatan stasiun pasang surut memiliki keterbatasan dalam beberapa hal. Keterbatasan tersebut diantaranya adalah jumlah, distribusi, dan jangkauan yang terbatas di daerah sekitar pantai, serta dampak lokal seperti pergerakan tanah secara vertikal (land subsidence) dan karakteristik pasang surut lokal (Woppelmann and Marcos, 2016).

Era satelit altimetri membawa revolusi dalam pengamatan variabilitas permukaan laut.
Pada tahun 1992, NASA (National Aeronautics and Space Administration) dan CNES (Centre National d'Etudes Spatiales) meluncurkan misi gabungan TOPEX / Poseidon dan kemudian pada tahun 2001 meluncurkan misi lanjutan yaitu satelit Jason-1. Pada tahun 2008 diluncurkan satelit Jason-2 / OSTM dengan tambahan bantuan dari EUMETSAT (Organisation for the Exploitation of Meteorological Satellites) dan NOAA (National Oceanic and Atmospheric Administration), kemudian dilanjut dengan misi satelit Jason 3. Misi satelit Jason Series ini mampu mengukur tinggi permukaan laut di sepanjang jalur permukaan yang sama dengan periode orbit yang berulang dalam 9,9156 hari di ketinggian sekitar $1336 \mathrm{~km}$ dengan sudut inklinasi $66^{\circ}$. Catatan data jangka panjang yang presisi ini membantu untuk studi pengamatan muka laut secara spasial dan temporal (Nerem, et.al., 2010).

Penelitian ini bertujuan untuk menganalisis tren kenaikan muka air laut Indonesia selama 25 tahun, yaitu tahun 1993-2018 berdasarkan data pengamatan satelit altimetri Topex/Poseidon, Jason 1, Jason 2, dan Jason 3, agar didapatkan tren kenaikan muka air laut di Indonesia yang akurat. Penelitian ini hanya menggunakan data altimetri dari Radar Altimeter Database System (RADS). Penggunaan data yang murni hanya melibatkan data altimetri tanpa data pengukuran langsung di lapangan ini didasarkan pada hasil penelitian L. Fenoglio-Marc (2010) berjudul "Sea Level Change and Vertical Motion from Satellite Altimetry, Tide Gauges and GPS in the Indonesian Region" yang menunjukkan bahwa data pengamatan satelit altimetri dan data insitu stasiun pasang surut memiliki nilai korelasi yang sangat kuat. Hal tersebut berarti bahwa pengukuran insitu meningkatkan kualitas data pengamatan altimetri, namun peningkatan yang ditunjukkan tidak terlalu signifikan (Fenoglio-Marc, et.al., 2010).

\section{METODE}

\section{Lokasi Penelitian}

Lokasi penelitian ini adalah seluruh laut di Indonesia dengan batas koordinat $13^{\circ} \mathrm{LU}-20^{\circ} \mathrm{LS}$ dan $90^{\circ} \mathrm{BT}-145^{\circ} \mathrm{BT}$. Lokasi penelitian terdiri dari 17.600 pulau dan garis pantai sepanjang $81.000 \mathrm{~km}$ (Dahuri, et.al., 2008). Lokasi penelitian dilewati oleh 43 pass orbit satelit altimetri Topex / 
Poseidon, Jason 1, Jason 2, dan Jason 3 dan ditunjukkan pada Gambar 1.

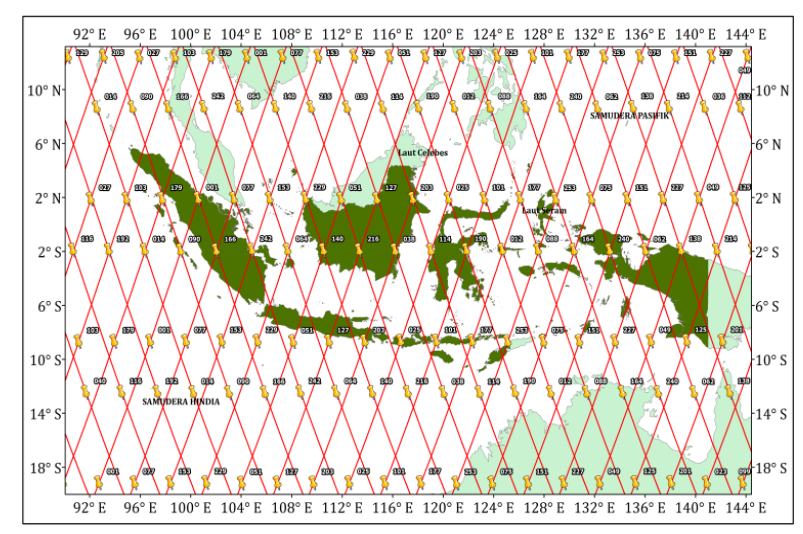

Gambar 1. Ground Track Satelit T/P dan Jason di Indonesia.

(Sumber: Centre National d'Etudes Spatiales 2016)

\section{Tahapan Penelitian}

Tahapan dari penelitian ini adalah sebagai berikut:

1. Pengumpulan Data

Pada tahap ini dilakukan pengumpulan datadata yang digunakan dalam penelitian ini, yaitu data RADS. Dataset RADS (Radar Altimeter Database System) berisi semua parameter koreksi data satelit altimetri serta nilai pengamatan satelit altimetri Jason 1, Jason 2, dan Jason 3 yang meliputi range dan altitude satelit dari referensi ellipsoid. Data model MSS juga diambil dari RADS. Set data berformat NetCDF yang nantinya akan diterjemahkan menggunakan bahasa MATLAB R2013. RADS merupakan sistem database data yang menyediakan data satelit altimetri berformat ASCII dari berbagai misi satelit altimetri. RADS dikembangkan oleh Delft Institute for EarthOriented Space Research dan NOAA Labaratory for Satellite Altimetry. Data RADS tersedia secara gratis di http://rads.tudelft.nl/rads/.

2. Penerapan Koreksi

Pada penelitian ini dipilih model koreksi terbaik dan paling akurat untuk penggunaan data altimetri di wilayah Indonesia. Perhitungan koreksi ini akan menghasilkan SSH (sea surface height) terkoreksi, yang kemudian digunakan untuk menghitung SLA (sea level anomaly). Semua perhitungan dilakukan menggunakan script sederhana di MATLAB R2013. Perhitungan yang dilakukan menggunakan formula sebagai berikut (Andersen, 2010):

$$
\Delta \mathbf{R G e o}_{\text {corrs }}=\Delta \mathbf{h}_{\text {dry }}+\Delta \mathbf{h}_{\text {wet }}+\Delta \mathbf{h}_{\text {iono }}+\Delta \mathbf{h}_{\text {sSB }}+
$$$$
\Delta \mathbf{h}_{\text {DAC }}+\Delta \mathbf{h}_{\text {tides }}+\Delta \mathbf{h}_{\text {RFO }}
$$

SSH $=\mathbf{H}-\mathbf{R}_{\text {obs }}-\Delta \mathbf{R G e o}_{\text {corrs }}$

dimana $\Delta \mathrm{h} \_d r y=$ dry trophospheric correction, $\Delta \mathrm{h}$ _wet $=$ wet trophospheric correction, $\Delta \mathrm{h} \_$iono $=$koreksi ionosfer, $\Delta \mathrm{h} \_\mathrm{SSB}=$ sea state bias, $\quad \triangle$ h_DAC $=$ dynamic atmospheric correction, $\Delta \mathrm{h}$ _tides $=$ koreki pasang surut, $\Delta \mathrm{h} \_$RFO $=$koreksi kerangka acuan offset, $\mathrm{h} \_\mathrm{SLA}$ = sea level anomaly, SSH = sea surface height, dan h_MSS = mean sea surface. Semua variabel tersebut memiliki satuan meter, dan dalam kebutuhan analisis satuan SLA di akhir dapat dikonversi menjadi mm.

Dry Trophospheric Correction (DTC) yang digunakan untuk perhitungan delay atmosfer pada jalur kering didapatkan dari NWM (Numerical Weather Model) yang dikembangkan oleh ERA-Interim pada grid $0,75 \times 0,75^{\circ}$ dengan range $-2,4$ hingga 2,1 meter. Wet Trophospheric Correction (WTC) yang digunakan untuk koreksi troposfer basah adalah model ERA-Interim dengan range -0,6 hingga 0 meter (Scharroo, 2010).

Koreksi ionosfer yang dipilih adalah model smoothed dual frequency yang mampu mengurangi variasi SLA hingga 2,5 cm2 hingga ke jarak $25 \mathrm{~km}$ dekat pantai. Range koreksi ini yaitu -0,4 hingga 0,04 meter (Handoko, et.al., 2017). Koreksi akibat Sea State Bias (SSB) yang dipilih adalah model Tran2012 karena mampu mengurangi variasi SLA untuk satelit Jason 1 sebesar $1 \mathrm{~cm} 2$ dan Jason 2 sebesar $2,5 \mathrm{~cm} 2$ (Handoko, et, al., 2017). Dynamic Atmospheric Correction (DAC) yang dipilih adalah model local mean of MOG2D dengan range -1 hingga 1 meter. Koreksi Tides meliputi ocean tides, load tides, solid tides, dan pole tides. Model ocean tides dan load tides yang digunakan adalah GOT4.10 dengan range -5 hingga 5 meter (Scharroo, 2010).

3. Perhitungan SLA

Sea level anomaly (SLA) dihitung menggunakan script sederhana di MATLAB R2013 dengan formula sebagai berikut:

$$
\mathbf{h}_{\text {SLA }}=\mathbf{S S H}-\mathbf{h}_{\text {MSS }}
$$

Model MSS yang digunakan dalam perhitungan adalah CNES-CLS11 untuk Topex/Poseidon dan CNES-CLS15 untuk Jason 1, Jason 2, dan Jason 3. Rentang MSS yang digunakan 200 hingga 200 meter [9]. Kemudian dilakukan kontrol kualitas dalam range -2 hingga 2 meter terhadap hasil SLA. Hal ini dilakukan untuk menghilangkan data yang outlier. Apabila nilai memenuhi 
akurasi maksimum dari masing-masing kualitas oleh Topex / Poseidon, Jason 1, Jason 2, dan Jason 3 maka akan dilanjutkan ke proses berikutnya. Apabila tidak memenuhi berarti perlu diulang kembali prosesnya untuk data yang outlier.

Tabel 1. Parameter Model Koreksi yang Digunakan

\begin{tabular}{|c|c|c|c|c|}
\hline Parameter & $T / P$ & Jason-1 & Jason-2 & Jason-3 \\
\hline DTC & $\begin{array}{l}\text { ERA- } \\
\text { Interim } \\
\text { DTC }\end{array}$ & $\begin{array}{l}\text { ERA- } \\
\text { Interim } \\
\text { DTC }\end{array}$ & $\begin{array}{l}\text { ERA- } \\
\text { Interim } \\
\text { DTC }\end{array}$ & $\begin{array}{c}\text { ERA- } \\
\text { Interim } \\
\text { DTC }\end{array}$ \\
\hline WTC & $\begin{array}{l}\text { ERA- } \\
\text { Interim } \\
\text { WTC }\end{array}$ & $\begin{array}{l}\text { ERA- } \\
\text { Interim } \\
\text { WTC }\end{array}$ & $\begin{array}{c}\text { ERA- } \\
\text { Interim } \\
\text { WTC }\end{array}$ & $\begin{array}{c}\text { ERA- } \\
\text { Interim } \\
\text { WTC }\end{array}$ \\
\hline Ionosfer & $\begin{array}{c}\text { smoothed } \\
\text { dual } \\
\text { frequency }\end{array}$ & $\begin{array}{c}\text { smoothed } \\
\text { dual } \\
\text { frequency }\end{array}$ & $\begin{array}{c}\text { smoothed } \\
\text { dual } \\
\text { frequency }\end{array}$ & $\begin{array}{c}\text { smooth } \\
\text { ed dual } \\
\text { frequen } \\
c y\end{array}$ \\
\hline SSB & $\begin{array}{l}\text { CLS non- } \\
\text { parametric }\end{array}$ & $\begin{array}{c}\text { Tran2012 } \\
\text { non- } \\
\text { parametric }\end{array}$ & $\begin{array}{c}\text { Tran2012 } \\
\text { non- } \\
\text { parametric }\end{array}$ & $\begin{array}{c}\text { Tran201 } \\
2 \text { non- } \\
\text { parame } \\
\text { tric }\end{array}$ \\
\hline DAC & $\begin{array}{l}\text { local mean } \\
\text { of } \mathrm{MOG} 2 \mathrm{D}\end{array}$ & $\begin{array}{l}\text { local mean } \\
\text { of MOG2D }\end{array}$ & $\begin{array}{l}\text { local mean } \\
\text { of } \mathrm{MOG} 2 \mathrm{D}\end{array}$ & $\begin{array}{c}\text { local } \\
\text { mean of } \\
\text { MOG2D } \\
\end{array}$ \\
\hline Tides & GOT4.10 & GOT4.10 & GOT4.10 & $\begin{array}{c}\text { GOT4.1 } \\
0\end{array}$ \\
\hline MSS & $\begin{array}{l}\text { CNES- } \\
\text { CLS11 }\end{array}$ & $\begin{array}{l}\text { CNES- } \\
\text { CLS15 }\end{array}$ & $\begin{array}{l}\text { CNES- } \\
\text { CLS15 }\end{array}$ & $\begin{array}{l}\text { CNES- } \\
\text { CLS15 }\end{array}$ \\
\hline
\end{tabular}

Sumber: Scharroo, RADS Data Manual 2016

\section{Intercalibrated}

Intercalibrated dilakukan dengan mengitung nilai bias pada cycle yang mengalami tandem misi. Bias ini dihitung menggunakan least square adjustment dari data yang overlap di dua satelit yaitu Topex / Poseidon dan Koreksi pada Jason 1, Jason 2, dan Jason 3 dihitung dengan rumus sebagai berikut (Masters, et.al., 2012):

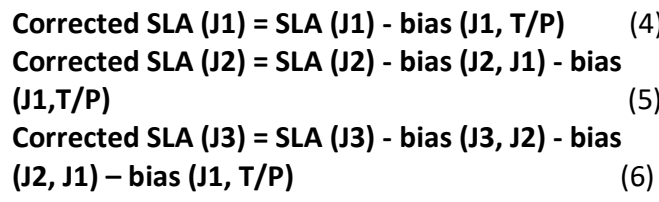

5. Time Series Decomposition

Metode dekomposisi yang digunakan dalam penelitian ini adalah STL ( $A$ Seasonal-Trend Decomposition Procedure Based on Regression) yaitu dengan pendekatan additive only. Pendekatannya adalah sebagai berikut (Makridakis, et.al., 1998):

$$
\boldsymbol{Y}_{\boldsymbol{t}}=\boldsymbol{S}_{\boldsymbol{t}}+\boldsymbol{T}_{\boldsymbol{t}}+\boldsymbol{E}_{\boldsymbol{T}}
$$

dimana $Y_{t}$ adalah data observasi, $S_{t}$ adalah seasonal, $T_{t}$ adalah trend, dan $E_{T}$ adalah remainder atau error.

Tahap ini dilakukan untuk menguraikan time series ke dalam berbagai komponen yaitu seasonal, trend, dan remainder. Metode ini menggunakan iterative loess smoothing untuk mendapatkan perkiraan tren dan kemudian loess smoothing lagi untuk mengekstrak komponen musiman aditif yang berubah. Penggunaan model ini dikarenakan STL memiliki ketahanan yang sangat tinggi terhadap data observasi yang ekstrem (Dokumentov and Hyndman, 2015). Dekomposisi dikerjakan menggunakan program $\mathrm{R}$ sehingga didapatkan trend SLA.

6. Tren Linier

Trend yang dihasilkan dari STL decomposition selanjutnya dihitung linier trendnya menggunakan ordinary least square untuk kemudian didapatkan nilai kecepatan SLA dari nilai koefisien variabel $x$, yaitu variabel waktu [14].

7. Analisis Hasil

Tahap terakhir dari penelitian ini adalah menganalisis hasil pengolahan data yang telah diperoleh. Analisis terhadap tren kenaikan muka air laut yang dihasilkan dapat menggambaran fenomena variabilitas permukaan laut di Indonesia.

\section{HASIL DAN PEMBAHASAN}

\section{Sea Level Anomaly}

Berdasarkan perhitungan SLA yang telah dilakukan, dengan model koreksi yang telah dijelaskan pada pembahasan sebelumnya, dihasilkan nilai rata-rata SLA per cycle di Indonesia yang ditunjukkan pada Gambar 2. SLA dari pengamatan Topex/Poseidon ditunjukkan dengan warna ungu, Jason 1 berwarna merah, Jason 2 berwarna hijau, dan Jason 3 berwarna biru.

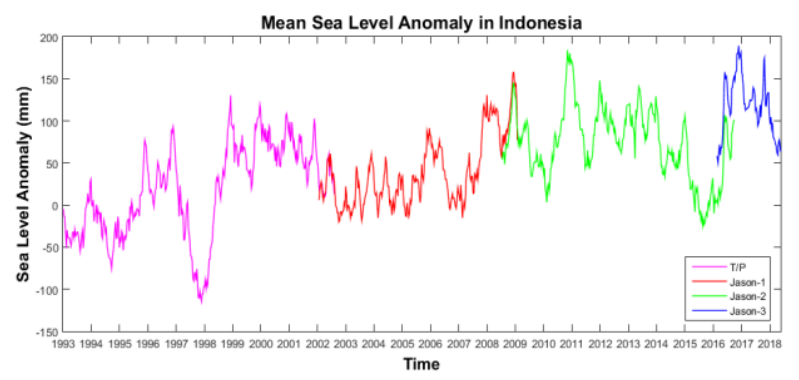

Gambar 2. Grafik Sea Level Anomaly

Gambar 2 menunjukkan bahwa rata-rata sea level anomaly di Indonesia hasil pengamatan Topex/Poseidon berada dalam range $-114,7$ hingga 130,5 mm. Sedangkan hasil pengamatan Jason 1 
berada dalam range -20,9 hingga 130,1 mm, Jason 2 berada dalam range -8.0 hingga $200,7 \mathrm{~mm}$, dan Jason 3 berada dalam range 25,1 hingga 154,7 mm.

Berdasarkan Gambar 2 juga diketahui bahwa terjadi lompatan data pada cycle yang mengalami tandem. Oleh karena itu perlu dilakukan intercalibrated untuk menyatukan data Topex/Poseidon, Jason 1, Jason 2, dan Jason 3.

\section{Intercalibrated}

Berdasarkan perhitungan bias didapatkan nilai biasnya adalah sebagai berikut:

$$
\begin{aligned}
& \operatorname{bias}(J 1, T / P)=0,7 \mathrm{~mm} \\
& \operatorname{bias}(J 2, J 1)=-17,1 \mathrm{~mm} \\
& \operatorname{bias}(J 3, J 2)=51,1 \mathrm{~mm}
\end{aligned}
$$

Hasil koreksi terhadap cycle yang mengalami tandem misi ditunjukkan pada Gambar 3. Gambar tersebut menunjukkan lompatan data tandem misi, dimana garis warna biru adalah data referensi dan garis warna hijau adalah data yang harus dikoreksi. Sedangkan, warna hitam adalah data yang telah terkoreksi.
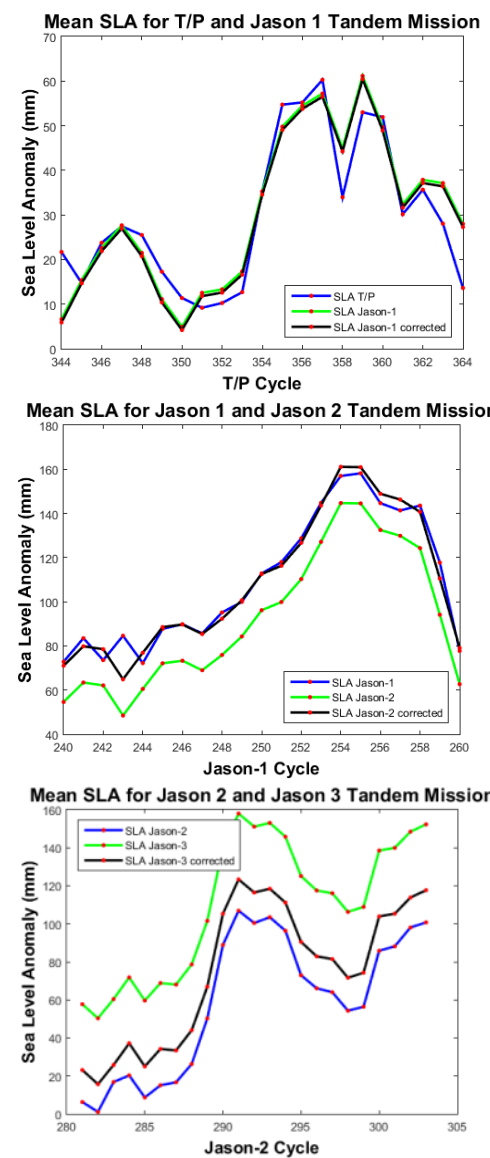

Gambar 3. Grafik Tandem Misi (1) T/P dan J1 (2) J1 dan J2 (3) J2 dan J3.

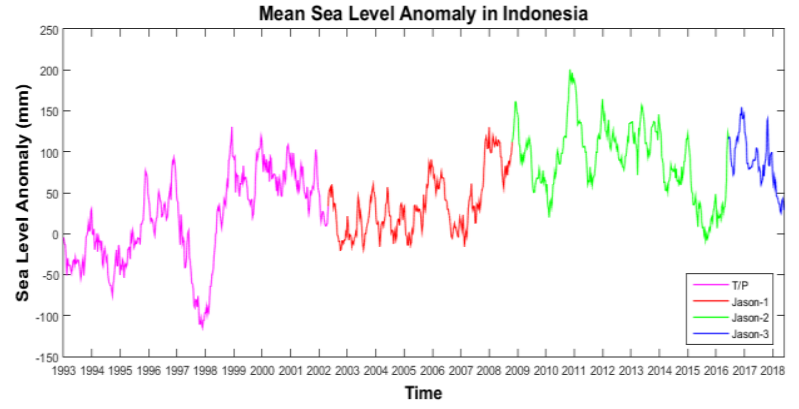

Gambar 4. Grafik Sea Level Anomaly Setelah Intercalibrated

Setelah dilakukan intercalibrated, nilai SLA dari Januari 1993 sampai Januari 2018 ditunjukkan pada Gambar 4. Dapat dilihat bahwa lompatan data sudah lebih smooth.

\section{Time Series Decomposition}

Setelah dilakukan STL decomposition di R, didapatkan grafik trend dan seasonal yang ditunjukkan pada Gambar 5.

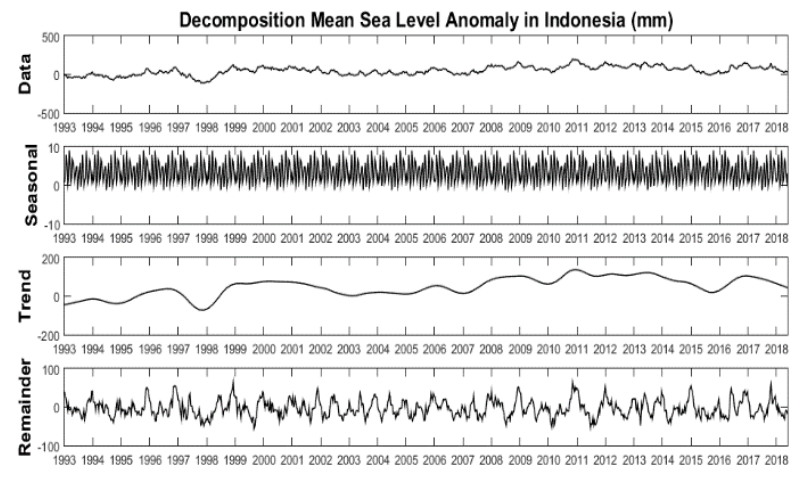

Gambar 5. Hasil Time Series Decomposition

\section{Seasonal}

Setelah dilakukan STL decomposition didapatkan grafik seasonal yang ditunjukkan Gambar 6 . Gambar tersebut menunjukkan bahwa pada setiap bulan Maret terjadi nilai sea level anomaly musiman dengan nilai $9,1 \mathrm{~mm}$, sedangkan pada setiap bulan Oktober terjadi nilai sea level anomaly musiman dengan nilai $-1,3 \mathrm{~mm}$.

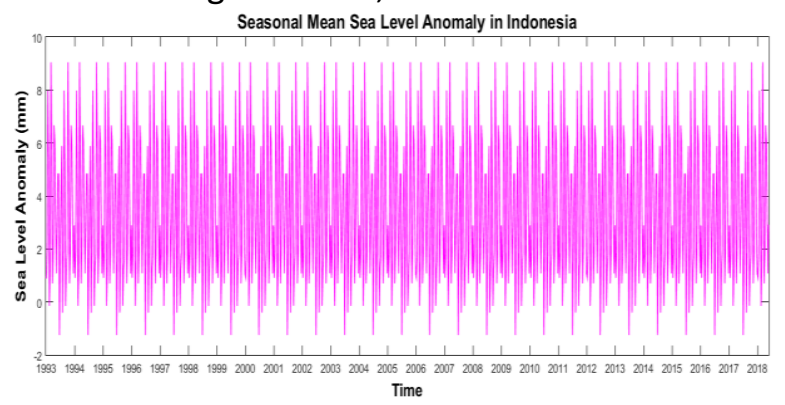

Gambar. 6. Grafik Seasonal Sea Level Anomaly. 


\section{Trend}

Hasil trend dari STL decomposition ditunjukkan pada Gambar 7. Berdasarkan trend diketahui bahwa nilai minimum SLA terjadi pada bulan November tahun 1997 yaitu -126,1 mm dan nilai SLA maksimum terjadi pada bulan November tahun 2010 yaitu $174,5 \mathrm{~mm}$.

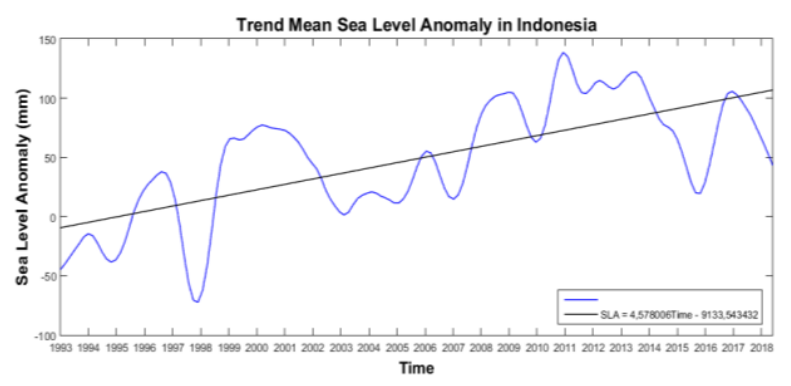

Gambar 7. Rata-rata Sea Level Rise Indonesia

Kemudian dihitung tren linier dari nilai trend tersebut sehingga menghasilkan persamaan sebagai berikut:

$$
y=4,6 x-9133,5
$$

Persamaan (8) menunjukkan persamaan dari tren linier yang menunjukkan tingkat nilai SLA terhadap waktu dengan y sebagai sea level anomaly dalam milimeter dan $\mathrm{x}$ sebagai variabel waktu dalam tahun. Dari Gambar 7 diketahui tren linier bernilai positif dari kemiringan garis ke arah kanan. Sehingga dari tren linier SLA didapat kecepatan sea level rise yang telah dihapus pola musimannya, yaitu dengan nilai $4,6 \mathrm{~mm} /$ tahun.

\section{KESIMPULAN}

Berdasarkan analisis dari hasil pengolahan data altimetri menggunakan Topex/Poseidon dan Jason Series dengan menghapus sinyal periodik menggunakan a seasonal-trend decomposition based on loess dapat disimpulkan bahwa laju/kecepatan sea level rise di Indonesia adalah $+4,6 \mathrm{~mm} /$ tahun. Nilai kecepatan positif ini menunjukkan bahwa sea level di Indonesia akan terus naik, sehingga diprediksi akan terjadi penenggelaman di beberapa kawasan di Indonesia. Oleh karena itu, perlu dilakukannya perencanaan penanggulangan sebelum terjadinya bencana tersebut.

Saran dari penulis mengenai keberlanjutan penelitian adalah penggunaan data time-series yang lebih panjang diperkiran dapat meningkatkan akurasi dari hasil estimasi ke depannya. Selain itu, pembatasan wilayah yang lebih spesifik dapat memperkirakan rata-rata kenaikan muka air laut di Indonesia yang lebih mencerminkan keadaan laut di Indonesia. Penggunaan data stasiun pasang surut juga mampu meningkatkan ketelitian data di daerah yang sangat dekat dengan daratan.

\section{UCAPAN TERIMA KASIH}

Penulis mengucapkan terima kasih kepada TUDelft, EUMETSAT, dan NOAA selaku pihak pengelola RADS (Radar Altimetry Database System) sebagai sumber data yang digunakan dalam penelitian ini.

\section{DAFTAR PUSTAKA}

Nicholls, R. J. "Impact of and responses to sea-level rise." Understanding Sea-Level Rise and Variability;, 2010: 17-44.

McGranahan, G., D. Balk, and B. Anderson. "The rising tide: Assessing the risks of climate change and human settlements in low elevation coastal zones." Environ. Urban, 2007: 17-37.

Dahuri, R., J. Rais, S. P. Ginting, and M. J. Sitepu. Pengelolaan SUmber Daya Pesisir dan Lautan secara Terpadu. Jakarta: Balai Pustaka, 2008.

Church, J. A., and N. J. White. "Sea-level rise from the late 19 th to the early 21 st century." Surv. Geophys, 2011: 585-602.

Woppelmann, G., and M. Marcos. "Vertical land motion as a key to understanding sea level change and variability." Rev. Geophys, 2016: 64-92.

Nerem, R. S., D. P. Chambers, C. Choe, and G. T. Mitchum. "Estimating Mean Sea Level Change from the TOPEX and Jason Altimeter Missions." Marine Geodesy, 2010: 435-446.

Fenoglio-Marc, L., T. Schone, J. Illigner, M. Becker, P. Manurung, and Khafid. "Sea Level Change and Vertical Motion from Satellite Altimetry, Tide Gauges and GPS in the Indonesian Region." Marine Geodesy, 2010: 137-150.

Andersen, O. B. "The DTU10 gravity field and mean sea surface." Second international symposium of the gravity field of the Earth (IGFS2). Alaska: Fairbanks, 2010.

Scharroo, R. RADS Data Manual. Netherlands: TUDelft, Handoko, E. Y., M. J. Fernandes, and C. Lazaro. "Assessment of Altimetric Range and Geophysical Corrections and Mean Sea Surface ModelsImpacts on Sea Level Variability around Indonesia Seas." Remote Sens, 2017: 102.

Masters, D., et al. "Comparison of Global Mean Sea Level Time Series from TOPEX/Poseidon, Jason-1, and Jason-2." Marine Geodesy, 2012: 20-41. 
Makridakis, S., S. C. Wheelwright, and R. J. Hyndman. Forecasting: Methods and Applications. United States of America: John Wiley \& Sons, 1998.

Dokumentov, A., and R. J. Hyndman. STR: A SeasonalTrend Decomposition Procedure Based on Regression. Australia: Department of Econometrics and Business Statistics, Monash University, 2015. 